\title{
A W-band GCPW MMIC Diode Tripler
}

\author{
Kun-You Lin, Huei Wang, Matthew Morgan*, Todd Gaier**, and Sander Weinreb** \\ Dept. of Electrical Engineering and Graduate Institute of Communication Engineering \\ National Taiwan University, Taipei, Taiwan, 10617, ROC \\ *Department of Electrical Engineering, California Institute of Technology, Pasadena, CA 91125, USA \\ **Jet Propulsion Laboratory, California Institute of Technology, Pasadena, CA, 91109, USA
}

\begin{abstract}
A W-band GCPW (grounded coplanar waveguide) MMIC diode tripler using GaAs PHEMT process is developed. An anti-parallel diode pair is used to produce third harmonic signal and a GCPW band pass filter is used to reject the spurious signal. The measured conversion loss is $18-20 \mathrm{~dB}$ from 87 to $102 \mathrm{GHz}$ at 14dBm input power. It is observed that if the filter were taken out, this tripler could be improved more than 5 $d B$ in conversion loss without significant affecting in rejection performance. In this case, the chip could be reduced at least by half to a miniature size, that is, from $1.5 \times 1 \mathrm{~mm}^{2}$ to about $0.8 \times 0.8 \mathrm{~mm}^{2}$.
\end{abstract}

\section{INTRODUCTION}

Signal source is a key component for various system applications such as radar communication, and radio astronomy. High frequency signal source is difficult to be achieved specially in millimeter wave region. The lower frequency signal source cascade with the frequency multipliers can be used to get the high frequency signal. Another approach is using the pushpush (1) or triple-push (2) configuration to achieve high frequency sources.

The frequency multipliers can be implemented in either passive or active type. The active type multipliers using transistors (7)-(10) have better conversion gain, however the bandwidth is more difficult to achieve due to the input impedance of transistors. On the other hand, passive type multipliers using diodes have wider bandwidth (3)-(6). Harmonic rejection is an important design consideration for the multipliers. It is widely reported using the quarter wavelength stub (3), (5)-(9) or balanced type (10) to reject the harmonic spurious signals. Some of the diode multipliers need dc bias to improve the performance (3)-(6). This paper presents a W-band GCPW (grounded coplanar waveguide) MMIC diode tripler without $\mathrm{dc}$ bias and demonstrates a measured conversion loss of $18-20 \mathrm{~dB}$ from 87 to $102 \mathrm{GHz}$. The conversion loss of this MMIC is comparable to the recently reported broadband tripler (4). Moreover, different from other reported W-band MMIC diode doublers and triplers (3)-(6), this MMIC is fabricated using a standard commercial available $0.15-\mu \mathrm{m}$ high linearity InGaAs/AlGaAs/GaAs PHEMT MMIC process and therefore it can be easily integrated with other
HEMT MMIC components such as amplifiers, oscillators into a single chip. Table 1 summarizes the previously reported W-band MMIC diode multipliers and this work. We estimate the size of our chip size can be reduced to $0.8 \times 0.8 \mathrm{~mm}^{2}$.

\section{DEVICE CHARACTERISTICS AND MMIC PROCESS}

The HEMT device used in this design is TRW standard $0.15-\mu \mathrm{m}$ high linearity $\mathrm{InGaAs} / \mathrm{AlGaAs} / \mathrm{GaAs}$ PHEMT MMIC process. The HEMT device has a typical unit current gain cutoff frequency $\left(\mathrm{f}_{\mathrm{T}}\right)$ of $70 \mathrm{GHz}$ and maximum oscillation frequency $\left(\mathrm{f}_{\max }\right)$ of $110 \mathrm{GHz}$, with a peak dc transconductance $\left(\mathrm{G}_{\mathrm{m}}\right)$ of $580 \mathrm{mS} / \mathrm{mm}$. The gate-drain breakdown voltage is $8 \mathrm{~V}$, and the drain current at peak $\mathrm{G}_{\mathrm{m}}\left(\mathrm{I}_{\mathrm{dspk}}\right)$ at $5-\mathrm{V}$ drain-source voltage is $280 \mathrm{~mA} / \mathrm{mm}$. Other passive components include thinfilm resistors, MIM capacitors, spiral inductors, and airbridges. The wafer is thinned to 4-mil for the gold plating of the backside and reactive ion etching via holes are used for dc grounding.

\section{CIRCUIT DESIGN}

An anti-parallel diode pair is used in this tripler to produce third harmonic signal and suppress the even harmonic signal of the input signal (3), (4), (11). The diode is simply implemented with the gate of HEMT as the anode and the drain and source connected together as the cathode. The 4-finger $28-\mu \mathrm{m}$ diode was used to design the tripler. The cut-off frequency is over $3 \mathrm{THz}$.

The anti-parallel diode pair can produce odd harmonic signal, so we can get not only third harmonic signal but 
also the fundamental signal from the anti-parallel diode pair (11). The tripler is implemented in GCPW. A GCPW band-pass-filter (BPF) is designed for spurious signal rejection. The filter consists of GCPW coupled lines and shunt short stubs (12). Via holes were added for suppressing the parallel-plate mode. The chip photo of the GCPW BPF is shown in Fig. 1.

The complete schematic of the tripler is shown in Fig. 2, and the chip photo is shown in Fig. 3. The chip size is $1.5 \mathrm{~mm} \times 1 \mathrm{~mm}$. The anti-parallel diode pair is shunted to ground. The $94-\mathrm{GHz}$ quarter wavelength open stub is shunt to the signal line to provide short circuit for third harmonic frequency. The BPF is series after the antidiode pair to reject the spurious signal.

The passive circuits included the BPF and the discontinuities of the transmission line were simulated by a full-wave EM simulator (Sonnet software) (13). The nonlinear simulation of the tripler was performed using harmonic balanced simulation of the AWR's circuit simulator Microwave Office (14).

\section{CIRCUIT MEASUREMENT}

The S-parameters of the GCPW BPF were measured via on-wafer probing. The measured return loss and insertion loss of the BPF are shown in Fig. 4. The return loss is better than $10 \mathrm{~dB}$ and the insertion loss is 5.5-8.2 dB from 87 to $97 \mathrm{GHz}$.

Fig. 5 shows the output power versus driving power for $84 \mathrm{GHz}, 87 \mathrm{GHz}$ and $105 \mathrm{GHz}$. The measured output power is $-2.8 \mathrm{dBm}$ while the driving power is $17.2 \mathrm{dBm}$ at $87 \mathrm{GHz}$. The best conversion loss at $87 \mathrm{GHz}$ is 18.1 $\mathrm{dB}$ while the output power is $-5.1 \mathrm{dBm}$.

Fig. 6 shows the output power versus output frequency with several different driving powers. The output power is better than $-5 \mathrm{dBm}$ from 87 to $102 \mathrm{GHz}$ while the driving power is $15.2-16 \mathrm{dBm}$. The conversion loss is better than $20 \mathrm{~dB}$ from 87 to $102 \mathrm{GHz}$ while the driving power is $14 \mathrm{dBm}$.

It is observed that the loss of the filter is higher than expected. If the loss of the filter can be reduced, the conversion loss of this tripler will be improved at least by $3 \mathrm{~dB}$ as shown in our original design. Moreover, if the output is connected to a WR-10 waveguide with a properly designed waveguide transition, such as reported in (15)-(16), the fundamental and second harmonic will be rejected by the waveguide, thus the output filter may not be necessary. Also, since from the measured filter data, the return loss are better than $10 \mathrm{~dB}$ from 87-97 $\mathrm{GHz}$, it is very likely the output matching will not affected much by taking out the filter. In this case, the chip size could be easily reduced by at least half in $\mathrm{x}$ dimension. Further meandering the input open stub could also reduce the y-dimension by $20 \%$. We estimate the chip size can be about $0.8 \mathrm{~mm}$ x $0.8 \mathrm{~mm}$ without degrading the performance significantly.

\section{SUMMARY}

A W-band GCPW MMIC frequency tripler has been designed, fabricated and tested. The tripler uses an antiparallel diode pair configuration and was fabricated by TRW standard 0.15- $\mu \mathrm{m}$ InGaAs/AlGaAs/GaAs PHEMT MMIC process. Since the tripler was fabricated by standard PHEMT MMIC process, it can easily be integrated with other MMIC circuits such as oscillators and amplifiers. The conversion loss of this tripler is 18$20 \mathrm{~dB}$ from 87 to $102 \mathrm{GHz}$ while the input power is 14 $\mathrm{dBm}$. It also has potential to redesign to a miniature size of about $0.8 \mathrm{~mm}$ x $0.8 \mathrm{~mm}$ with a similar performance.

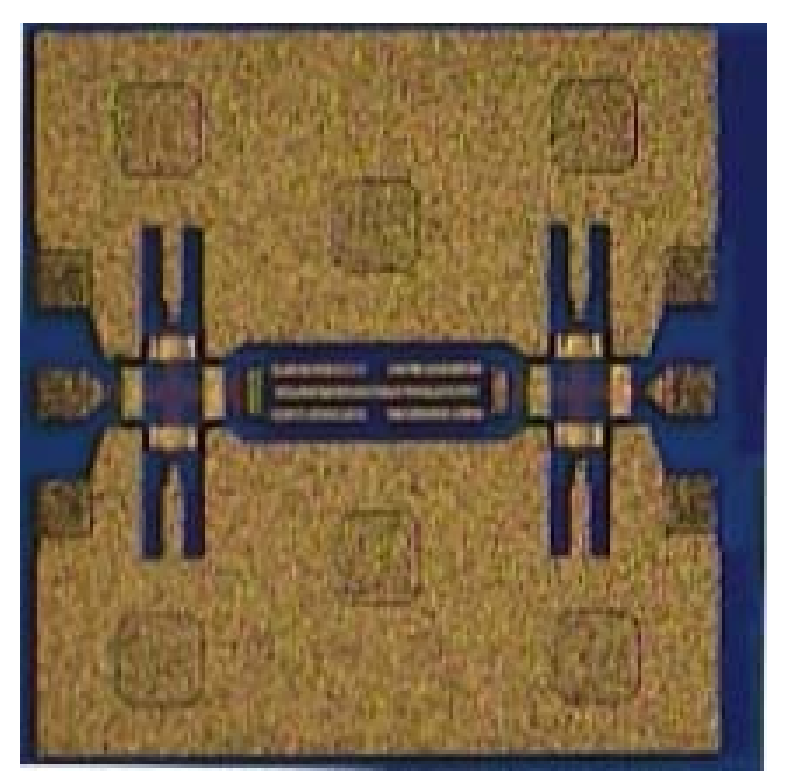

Fig. 1. The photo of the GCPW band pass filter.

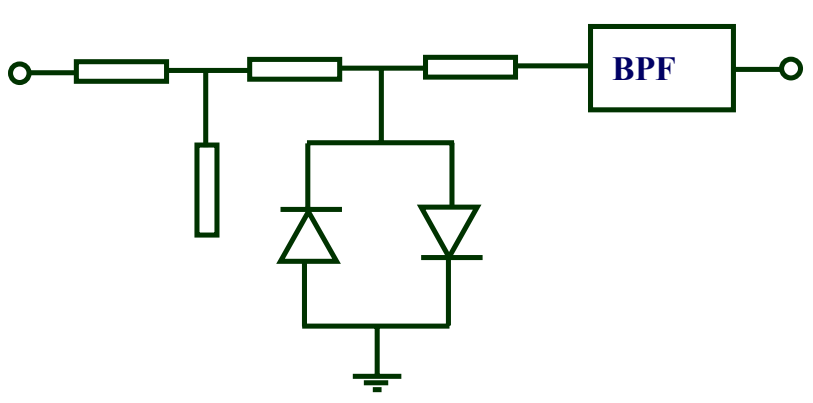

Fig .2. The schematic of the $W$-band GCPW tripler. 


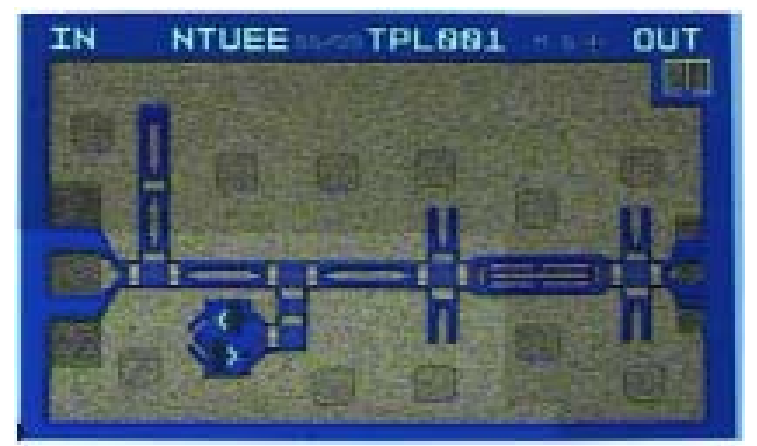

Fig. 3. The chip photo of the W-band GCPW tripler with a chip size of $1.5 \mathrm{~mm} \times 1 \mathrm{~mm}$.

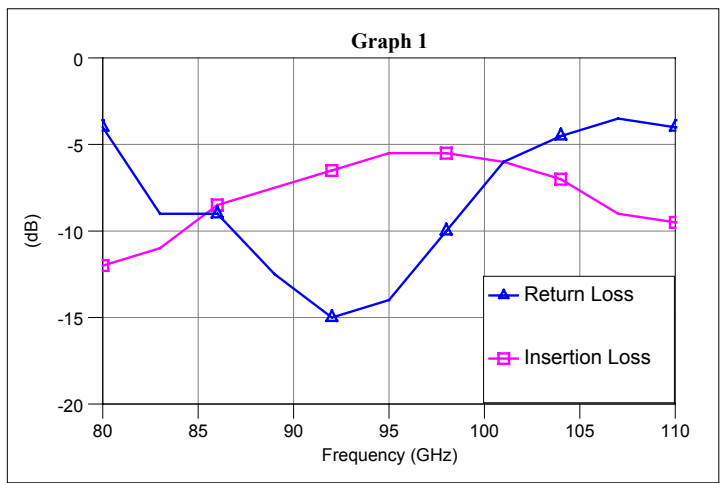

Fig. 4. The measured results of the GCPW BPF.

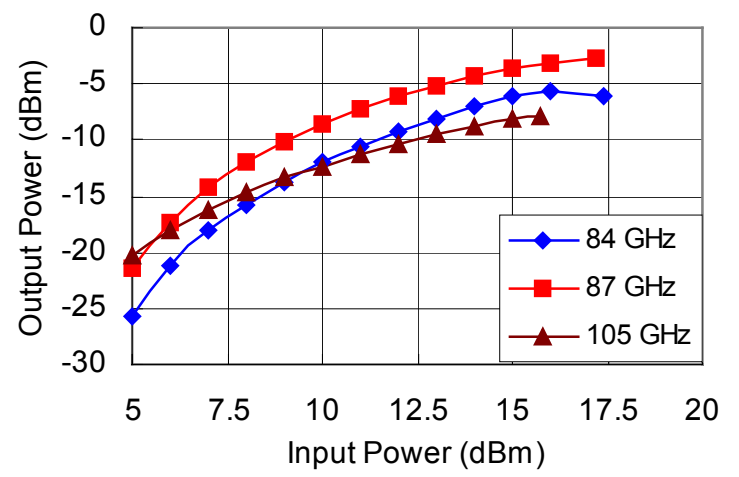

Fig. 5. Output power versus driving power.

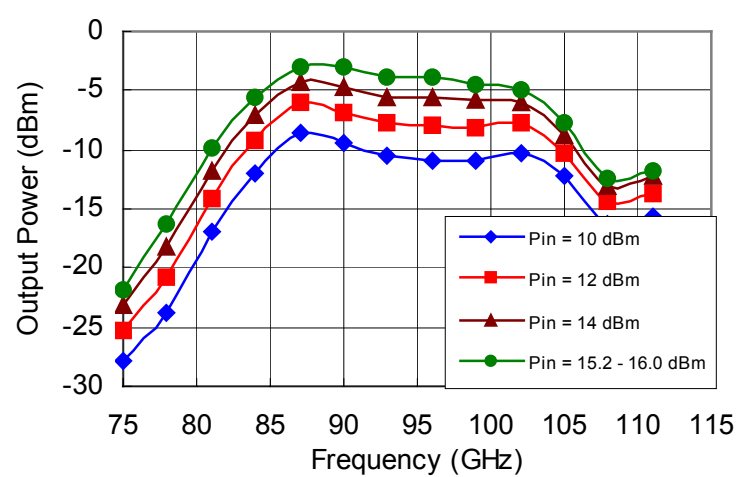

Fig. 6. Output power versus output frequency for several different driving powers.

\section{ACKNOWLEDGEMENT}

This work is supported in part by Research Projects of National Science Council of Republic of China. (Project no.: NSC 88-2219-E-002-015). The MMIC foundry service is provided by TRW Inc. through the Chip Implement Center (CIC) in Taiwan. The authors would like to thank Dr. Ying-Zung Juang of CIC and Mr. Chieh Chao Liu of Airwave Technology for their MMIC foundry coordination effort, and Mr. Dow-Chih Niu of Chung-Shan Institute of Science and Technology for his help in preliminary measurement of the chip.

\section{REFERENCES}

(1) K. W. Kobayashi, A. K. Oki, L. T. Tran, J. C. Cowels, A. Gutierrez-Aitken, F. Yamada, T. R. Block, and D. C. Streit, "A 108-GHz InP-HBT monolithic push-push VCO with low phase noise and wide tuning bandwidth," IEEE J. Solid-State Circuits, vol. 34, pp. 1225-1232, Sept. 1999.

(2) Yu-Lung Tang, and Huei Wang, "Tripler-push oscillator approach: theory and experiments," IEEE J. Solid-State Circuits, Vol. 36, pp. 1472-1479, Oct. 2001.

(3) Marvin Cohn, Ronald G. Freitag, H. George Henry, James E. Degenford and David A. Blackwell, "A $94 \mathrm{GHz} M M I C$ tripler using anti-parallel diode arrays for idler separation," 1994 IEEE International Microwave Symposium Digest, vol. 2, pp. 763-766.

(4) Matthew Morgan, and Sander Weinreb, "A full waveguide band MMIC tripler for 75-110 GHz," 2001 IEEE International Microwave Symposium Digest, vol. 1, pp. 103-106.

(5) John Papapolymerou, Jack East, Linda P. B. Katehi, “ $A$ high-power $W$-band monolithic FGC doubler," IEEE Microwave and Guided Wave Letters, Vol. 10, pp. 195197, May, 2000. 
(6) Seng-Woon Chen, Thomas Ho, Fred R. Phelleps, Jack L. Singer, Krishna Pande, Paul Rice, James Adair, and Mohammad Ghahremani, "A high-performance 94-GHz MMIC doubler," IEEE Microwave and Guided Wave Letters, Vol. 3, pp. 167-169, June, 1993.

(7) Y. Campos-Roca, L. Verweyen, M. Fernández-Barciela, E. Sánchez, M. C. Currás-Francos, W. Bronner, A. Hülsmann, and M. Schlechtweg "An optimized 25.5-76.5 GHz PHEMT-based coplanar frequency tripler," IEEE Microwave and Guided Wave Letters, Vol. 10, pp. 242244, June, 2000.

(8) Ali Boudliaf, Didier Bachelet and Christian Rumelhard, " $A$ high-efficiency and low-phase-noise 38-GHz PHEMT MMIC tripler," IEEE Trans. Microwave Theory Tech., vol. MTT-48, pp 2546-2553, Dec. 2000.

(9) Vesna Radisic, Miro Micovic, Ming Hu, Paul Janke, Catherine Ngo, Loi Nguyen, Lorene Samoska and Matthew Morgan, "164-GHz MMIC HEMT doubler," IEEE Microwave and Wireless Components Letters, Vol. 11, pp. 241-243, June, 2001.

(10) Y. Campos-Roca, L. Verweyen, M. Fernandex-Barciela, W. Bischof, M. C. Curras-Francos, E. Sanchez, A. Hulsmann, and M. Schlechtweg, "38/76 GHz PHEMT MMIC balanced frequency doubler in coplanar technology," IEEE Microwave and Guided Wave Letters, Vol. 10, pp. 484-486, Nov., 2000.
(11) Marvin Cohn, James E. Degenford, and Burton A. Newman, "Harmonic mixing with an antiparallel diode pair," IEEE Trans. Microwave Theory Tech., vol. MTT-23, pp 667-673, Aug. 1975.

(12) Khelifa Hettak, Nihad Dib, Abdul-Fattah Sheta, and S. Toutain, "A class of novel uniplanar series resonators and their implementation in original applications," IEEE Trans. Microwave Theory Tech., vol. MTT-46, pp 1270-1276, Sep. 1998.

(13) Sonnet User's Manual, Release 6.0, Sonnet Software Inc., Liverpol, NY, April 1999.

(14) Microwave Office VoltaireXL/LS $S^{T M}$ User's Guide, Applied Wave Research, Inc.

(15) Yoke-Choy Leong, and Sander Weinreb, "Full band Waveguide-to-microstrip probe transistion," 1999 IEEE International Microwave Symposium Digest, vol. 4, pp. 1435-1438.

(16) Pin-Pin Huang, Tian-Wei Huang, Huei Wang, Eric W. Lin, Yonghui Shu, Gee S. Dow, Richard Lai, Michael Biedenbender and Jeffery H. Elliot, "A 94-GHz $0.35-W$ power amplifier module," IEEE Trans. Microwave Theory Tech., vol. MTT-45, pp 2418-2423, Dec. 1997.

Table 1

The summary of previously reported W-band MMIC diode multipliers and this work.

\begin{tabular}{|c|c|c|c|c|c|}
\hline Paper & (3) & (4) & (5) & (6) & This work \\
\hline $\begin{array}{l}\text { Frequency } \\
\text { multiples }\end{array}$ & $\mathrm{x} 3$ & $\mathrm{x} 3$ & $\mathrm{x} 2$ & $\mathrm{x} 2$ & $\mathrm{x} 3$ \\
\hline Device & $\begin{array}{c}\text { Schottky vertical } \\
\text { diode }\end{array}$ & $\begin{array}{l}\text { BES Schottky } \\
\text { diode }\end{array}$ & $\begin{array}{l}\text { GaAs varactor } \\
\text { Schottky diode }\end{array}$ & $\begin{array}{l}\text { Varactor diode } \\
\text { (doping tuning } \\
\text { for efficiency) }\end{array}$ & $\begin{array}{c}\text { GaAs diode } \\
\text { PHEMT MMIC } \\
\text { process } \\
\end{array}$ \\
\hline $\begin{array}{c}\text { Transmission } \\
\text { line }\end{array}$ & Microstrip line & $\begin{array}{l}\text { Microstrip line } \\
\text { and GCPW }\end{array}$ & $\begin{array}{l}\text { Finite ground } \\
\text { CPW }\end{array}$ & Microstrip line & GCPW \\
\hline $\begin{array}{c}\text { Output frequency } \\
\text { range }(\mathrm{GHz})\end{array}$ & 97 & $75-110$ & $70-80$ & 94 & $87-102$ \\
\hline DC bias & Yes & Yes & Yes & Yes & No \\
\hline Output power & $\begin{array}{c}19 \mathrm{dBm} \text { at } 97 \\
\mathrm{GHz}\end{array}$ & $>-4 \mathrm{dBm}$ & $\begin{array}{c}20.6 \mathrm{dBm} \text { at } 74 \\
\mathrm{GHz}\end{array}$ & $\begin{array}{c}18.1 \mathrm{dBm} \text { at } 94 \\
\mathrm{GHz}\end{array}$ & $>-5 \mathrm{dBm}$ \\
\hline $\begin{array}{c}\text { Conversion loss } \\
\text { over the band }\end{array}$ & - & $<20 \mathrm{~dB}$ & $<12 \mathrm{~dB}$ & - & $<20 \mathrm{~dB}$ \\
\hline $\begin{array}{c}\text { Best conversion } \\
\text { loss } \\
\end{array}$ & $12 \mathrm{~dB}$ at $97 \mathrm{GHz}$ & $\begin{array}{c}16.2 \mathrm{~dB} \text { at } 85 \\
\mathrm{GHz}\end{array}$ & $\begin{array}{c}9.9 \mathrm{~dB} \text { at } 74 \\
\mathrm{GHz}\end{array}$ & $6 \mathrm{~dB}$ at $94 \mathrm{GHz}$ & $\begin{array}{c}18.1 \mathrm{~dB} \text { at } 87 \\
\mathrm{GHz}\end{array}$ \\
\hline Chip size $\left(\mathrm{mm}^{2}\right)$ & - & $2 \times 0.74$ & - & - & $1.5 \times 1 *$ \\
\hline
\end{tabular}

* potential to reduce to $0.8 \mathrm{~mm} \times 0.8 \mathrm{~mm}$ 